\title{
Estimation of the number of ovipositing females per fruit in the Mediterranean fruit fly Ceratitis capitata Wied. (Diptera: Tephritidae)
}
A. Civetta, ${ }^{*}$
J. C. Vilardi, $* \dagger \S$
B. O. Saidman, ${ }^{*} \dagger$
C. A. Leanza* and
J. L. Cladera

\author{
* Depto. Cs. Biologicas, Fac. Cs. Exactas y Naturales, \\ Universidad de Buenos Aires, 1428 Buenos Aires, \\ Rep. Argentina. \\ $\ddagger$ Departamento de Genética, INTA-Castelar, CC 25 , \\ Castelar, Prov. Buenos Aires, Rep. Argentina.
}

The larvae of $\boldsymbol{C}$. capitata occupy a discontinuous environment constituted by rotting fruits of several plant species. The consequences of this condition on the genetic structure were studied in a natural population by analyzing the polymorphism at the Est-1 (pupal esterase) locus by means of Wright's fixation indices. The results indicate that each fruit is colonized by a finite and small number of inseminated females (about four). The relations among the corresponding $F_{I S}, F_{I T}$ and $F_{S T}$ indices of each one of the three alleles detected in the population was not the same and the genotypic frequencies in the whole population differed from Hardy-Weinberg expectations, suggesting that some kind of selection might be acting on the Est-1 locus or linked loci.

\section{INTRODUCTION}

Ceratitis capitata is a widespread pest feeding on a wide range of fruits of commercial value. Although research on methods of genetic control of this organism is in progress in several laboratories all over the world, the study of the genetic structure and the adaptive strategy of natural populations have not received enough attention in this species.

The population genetics approach is of great importance since it may contribute useful information, such as the effective population sizes, the migration rates among neighbouring populations, the origin of colonizing populations, the occurrence of selective differences among genotypes, etc.

One of the requirements to perform an analysis of the population structure is the occurrence of genetic variation for some discrete character such as chromosome configurations or isozymal markers. This kind of variation is very often found in organisms such as Drosophila, a genus where

\footnotetext{
$\dagger$ Member of the Carrera del Investigador, Consejo Nacional de Investigaciones Cientificas y Técnicas.

$\S$ To whom correspondence should be addressed.
}

population genetics studies are most abundant (see Dobzhansky et al., 1980; Hedrick, 1983; etc.). In C. capitata, on the contrary, a very low degree of genetic variation has been detected in most studies using isozyme electrophoresis (Morgante et al., 1981; Kourti et al., 1985; Gasperi et al., 1987; Saidman et al., 1987) and the few studies on polytene chromosomes (Bedo, 1986; Zacharopoulou, 1987) have not contributed to population genetic analyses yet. However, Cladera (1981) described genetic variation for a pupal esterase locus in laboratory strains, which suggested the possibility of finding such variation in natural populations too.

Given the occurrence of genetic variation, the genetic structure of $C$. capitata may be studied taking advantage of its reasonably well known ecology. Natural populations of this species do not occupy a uniform environment. Rather, this environment is divided into a finite number of discrete, ephemeral and heterogeneous patches (the fruits) each one of them used as a breeding and feeding site by an unknown, but probably small, number of individuals (Feron, 1962). Indeed, C. capitata feeds and breeds on the maturing fruits of several commercial and wild plants. Each rotting fruit is quite ephemeral and, most 
probably, useful for only one generation, with a relatively narrow oviposition window.

In this paper the occurrence of variation for the pupal estarase locus (Est-1) was confirmed in an Argentine population and an analysis of the structure was performed by means of the F-statistics (Nei 1977; Nei and Chesser 1983). This method allows one: (1) to quantify the genetic differentiation among breeding sites, (2) to determine whether the heterogeneity for allelic frequencies has occurred at random or whether any other process such as selection must be invoked, and (3) to estimate the average number of mating pairs that contribute to the population at each breeding site.

\section{MATERIALS AND METHODS}

The collection site was located at Castelar, $25 \mathrm{~km}$ West of Buenos Aires, República Argentina. It is a plantation of peach and peach $\times$ almond hybrid trees at the INTA-Castelar Experimental Station. The area sampled involved two blocks of approximately 1 ha each, one of peach and the other of hybrid trees.

About 60 maturing fruits found to host $C$. capitata larvae were collected and brought to the laboratory on 9 February 1988. In order to avoid competition as much as possible and to increase the number of pupae to be obtained from each substrate, the fruits were opened and placed on a dish with $40 \mathrm{ml}$ of medium (Terán, 1977). The dish with the rotting fruit was placed into a cylindrical container with a sandy litter into which the third instar larvae jump just before becoming pupae. Each fruit received an identifying number indicating also the tree from which it came.

Each rotting fruit was observed every two days during 2 weeks and the pupae obtained were picked up and frozen in liquid air until the electrophoretic assay was performed. Only the fruits from which the genotype of at least five pupae could be obtained were included in the analysis. Thus, nine peaches from five trees and eight fruits from five hybrid trees were finally chosen.

The genetics of the Est-1 locus was described by Cladera (1981) employing starch gel electrophoresis. In the present study a better separation of bands was obtained using 7 per cent polyacrylamide gels.

In laboratory strains, Cladera (1981) described two alleles, testing through progeny analysis the genetic basis of this system. In the present study chemical evidence was considered to confirm the homology of the bands observed in the natural population with those of the laboratory strains. These involved the use of six different substrates: 1-naphthyl acetate (1-NA), 2-naphthyl acetate (2NA), 1-naphthyl meristate (1-NM), 1-naphthyl laurate (1-NL), 1-naphthyl butirate (1-NB) and naphtol ASD-acetate (Naphtol-ASD). The criterion employed was that bands with similar affinities with all substrates are to be considered as produced by the same locus (allozymes) (see Saidman and Naranjo, 1982).

\section{DATA ANALYSIS}

The genetic structure of the studied population was analysed by means of Wright's $(1951,1965)$ fixation indices $\left(F_{I S}, F_{I T}\right.$ and $\left.F_{S T}\right)$. These indices were defined by Wright as the correlation between uniting gametes relative to the subpopulations (= rotting fruits) ( $\left.F_{I S}\right)$ and relative to the total populations $\left(F_{I T}\right) . F_{S T}$, in time, is the correlation of random gametes within subdivisions relative to the total population.

Nei (1977) has shown that F-statistics can be reformulated and defined as a function of observed and expected heterozygosites, rather than correlation of uniting gametes. Nei's method may be applied to any situation independently of the occurrence of selection or of the number of alleles segregating at a locus. However, this method does not take into account the differences in sample sizes among subpopulations. To overcome this difficulty, Nei and Chesser (1983) proposed a correction for the estimation of the indices.

In the present analysis the method employed was that of Nei and Chesser (1983) and calculations were made using the computer program proposed by Vilardi (1989).

\section{RESULTS}

\section{The Est- 1 locus in the wild population}

The wild population here studied proved to be polymorphic for the Est-1 locus, showing three alleles (fig. 1). Two of them, Est $-1^{\mathrm{a}}$ and Est $-1^{\mathrm{b}}$ are the same as those described by Cladera (1981); a third allele $\left(E s t_{-}{ }^{c}\right)$ was detected in this population for the first time.

Since this locus is expressed in the prereproductive stage and Est $-1^{\mathrm{c}}$ occurs in a frequency relatively low in the population sampled, homozygous lines have not been obtained so far which allow demonstration of homology of this allele 

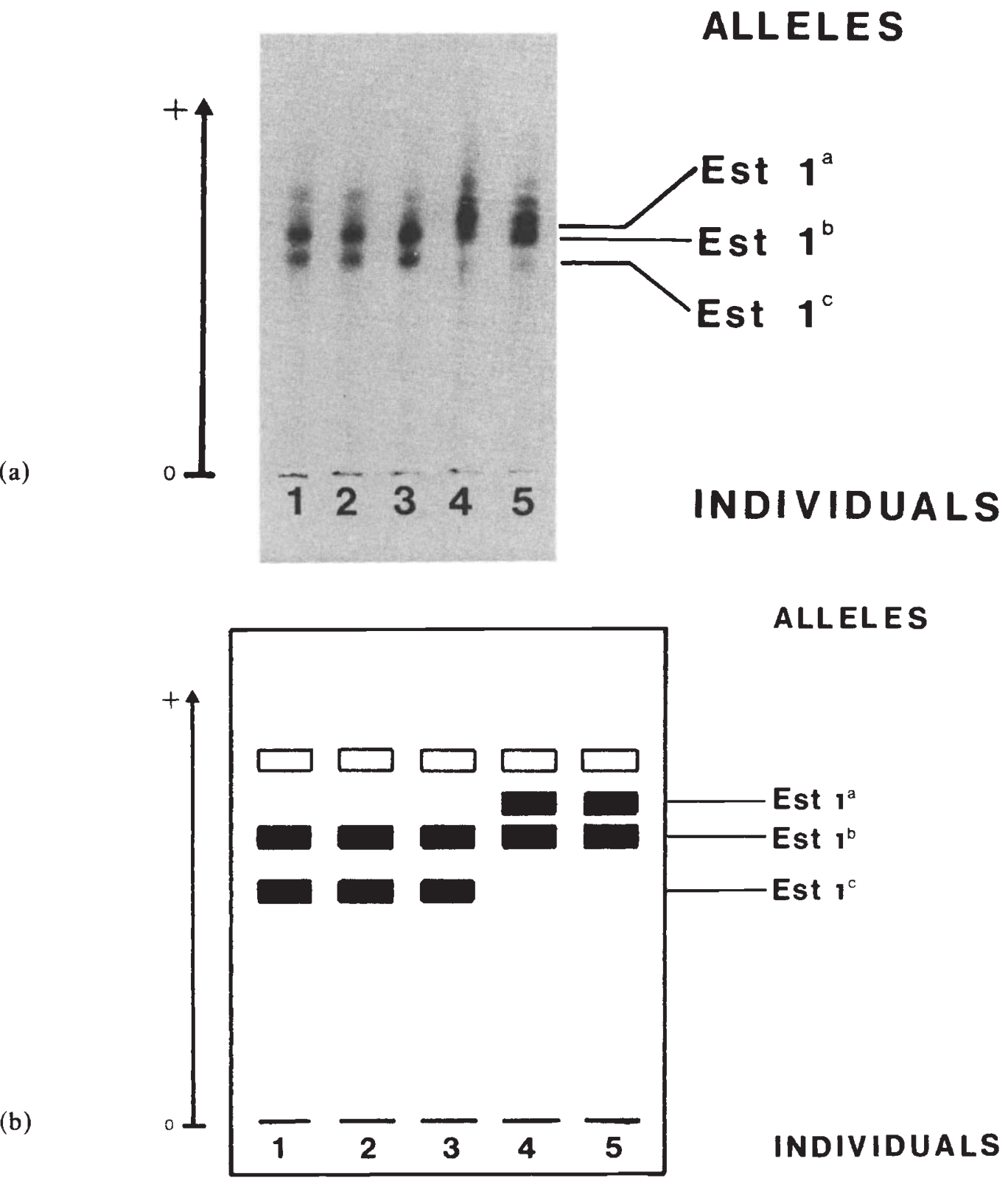

Figure 1 (a) Zymogram showing the bands corresponding to the locus Est-1. A light band faster than that corresponding to the allele Est $-1^{\mathrm{a}}$ is also observed, but its genetic basis has not been studied so far. (b) Schematic representation of the zymogram.

with Est $-1^{\mathrm{a}}$ and $E s t-1^{\mathrm{b}}$ by means of progeny tests. However, though no controlled crosses were made, the homology of this new allele with those previously described is supported by chemical evidences and the combinations of bands observed. The relative intensities of reaction of all three alleles with the different substrates were as follows: 2-NA $>1-\mathrm{NA}>1-\mathrm{NB}>1-\mathrm{NM}=1-\mathrm{NL}>$ Naphtol ASD. The patterns observed involved either one band $\left(\mathrm{EST}-1^{\mathrm{a}}, \mathrm{EST}-1^{\mathrm{b}}\right.$ or EST $\left.-1^{\mathrm{c}}\right)$ or two bands (EST- $1^{\mathrm{a}}-\mathrm{EST}-1^{\mathrm{b}}$, EST- $1^{\mathrm{a}}-\mathrm{EST}-1^{\mathrm{c}}$ or EST- $1^{\mathrm{b}}$-EST$\left.1^{\mathrm{c}}\right)$. Three bands patterns were not observed among about 350 sampled individuals.

\section{Within fruit analysis}

Table 1 shows the raw data obtained from the electrophoretic analysis of 1 or 2 days old pupae 
Table 1 Absolute genotype frequencies, estimates of $\mathrm{F}_{\mathrm{ISi}}$ and relative allelic frequencies for the Est-1 locus in pupae of Ceratitis capitata taken directly from the rotting fruits of peach $(\mathrm{A})$ and peach $\times$ almond hybrid (B) trees. Letter headings $(\mathrm{A}, \mathrm{D}$, etc.) identify the tree from which fruits were collected

A

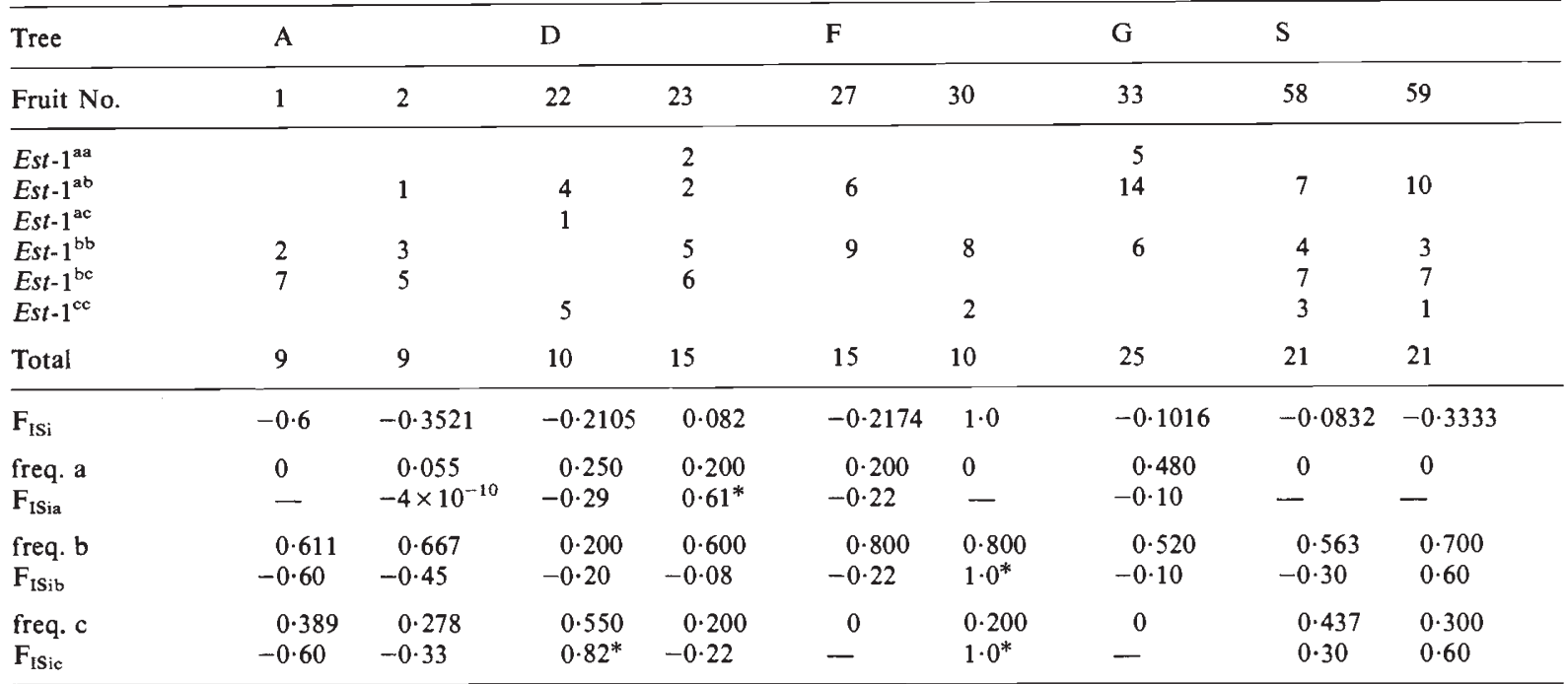

B

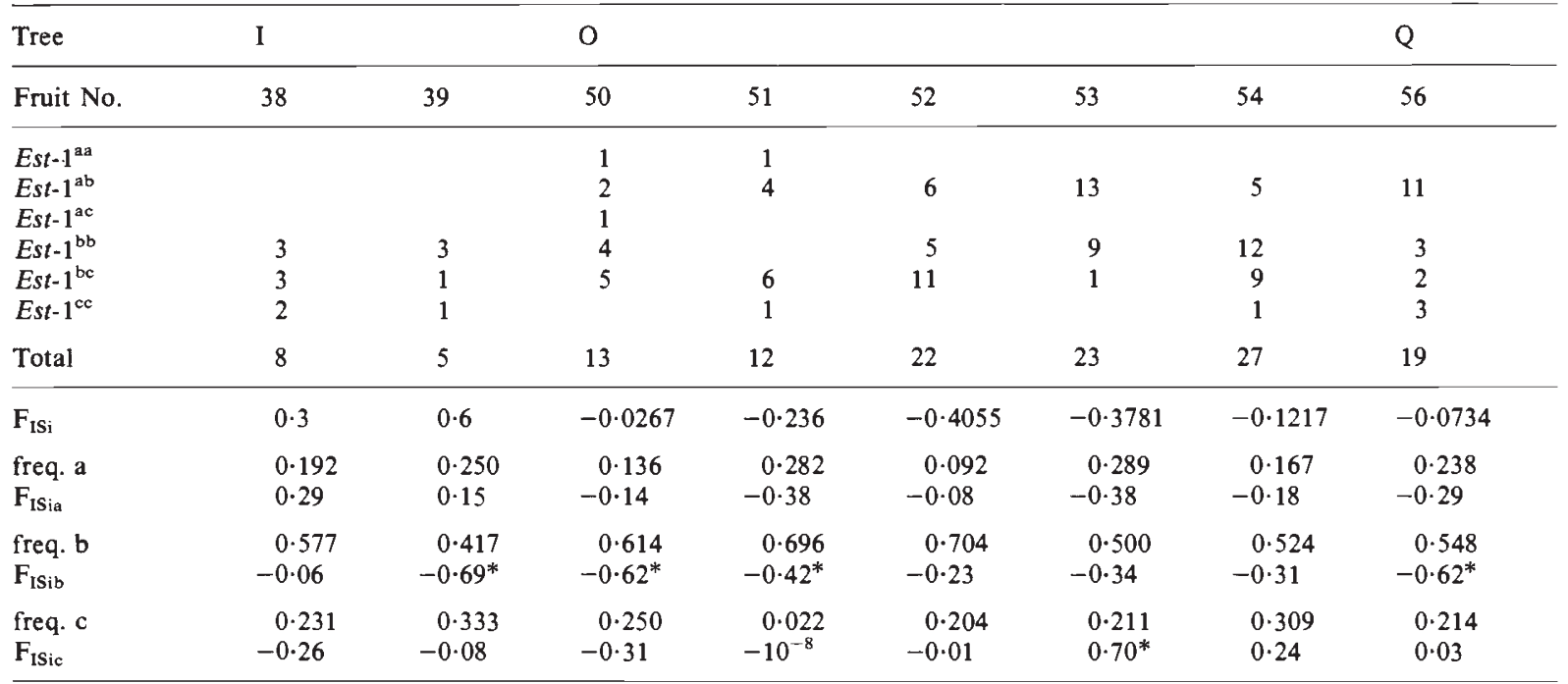

* Significant $\mathrm{F}_{\mathrm{ISik}}$ values.

taken after jumping from the rotting fruits. The number of individuals of each genotype along with the unified fixation index for all alleles in every rotting fruit $\left(\mathrm{F}_{\mathrm{ISi}}\right)$ are indicated. This index measures the discrepancy between the observed and expected (according to Hardy-Weinberg) frequencies of heterozygotes in each fruit. Negative values indicate an excess of heterozygotes and vice versa (Nei 1977).
About 70 per cent of rotting fruits showed excess of heterozygotes. This determined that the weighted average of $F_{I S i}\left(F_{I S}\right)$ was negative. Negative $F_{I S}$ values are expected when the number of inseminating females breeding on a single substrate is relatively small (see Robertson, 1965; Rassmussen, 1979; Santos et al., 1989). In such cases, the frequency of heterozygotes, in absence of selection, will exceed Hardy-Weinberg expecta- 
tions by a proportion of $1 / 2 N$ where $N$ is the effective number of parents per subpopulation ( $=$ fruit). However, in the present case the excess of heterozygotes seems not to be of general occurrence when the alleles are considered separately.

Est $-1^{\text {a }}$ was present in only 13 of the rotting fruits analysed, and the excess of heterozygotes was observed in ten of them. The weighted average of $F_{I S i}$ values for this allele, $F_{I S . a}$ was negative, though the only significant $F_{I S i a}$ was positive, and tested by the method of Li and Horvitz (1953), the average was not significant (see below). Est-1 ${ }^{\text {b }}$ showed excess of heterozygotes in 14 fruits. In 4 of them the $F_{I S i b}$ was significant and a sign test (comparison of expected $0 \cdot 5: 0.5$ distribution against the observed by means of a chi-square test for goodness of fit) indicated a tendency towards an overall excess of heterozygotes $\left(\chi_{1}^{2}=7 \cdot 1 ; P=\right.$ $0 \cdot 008)$. The $F_{I S . b}$ was markedly negative $(-0 \cdot 2)$. On the contrary, $F_{I S . c}$ was strongly positive. The individual values $\left(\mathrm{F}_{\mathrm{ISic}}\right)$ were positive in seven and negative in eight fruits, but three of the positive values were significant.

This differential behaviour of the three alleles suggests that the small number of breeding parents on each fruit is not the only factor determining the deviations from the expected genotypic frequencies in each rotting fruit.

\section{Among fruit analysis}

The allelic frequencies were compared among substrates by means of a contingency table analysis. The results indicated highly significant heterogeneity among rotting fruits $\left(\chi_{32}^{2}=104 \cdot 28\right.$; $\left.P<10^{-6}\right)$. This differentiation was mainly due to alleles Est $-1^{\mathrm{a}}$ and $E s t-1^{\mathrm{c}}$ which were absent in some fruits, while Est-1 ${ }^{\mathrm{b}}$ was present in all subpopulations.

\section{Analysis of population structure}

The average allelic frequencies as well as F-statistics obtained from the within and among fruit analysis are given in table 2. As previously observed in the within fruit analysis, F-statistics vary with allele. The significance of the averages $\left(F_{I S . k}\right)$ may be tested according to the method of Li and Horvitz (1953) $\left(\chi^{2}=N \mathrm{~F}_{\text {IS }}^{2}\right)$. The chi-square values for the alleles Est $-1^{\mathrm{b}}$ and Est-1 ${ }^{\mathrm{c}}$ are significant $\left(\chi_{1}^{2}=10.29\right.$ and 5.07 respectively, $P<$ $0 \cdot 05)$. Furthermore, according to the within-fruit analysis, a tendency towards an excess of heterozygotes involving Est-1 ${ }^{\mathrm{b}}$ and a deficiency of hetero-
Table 2 F-statistics for the Est-1 locus of $C$. capitata

\begin{tabular}{|c|c|c|c|c|}
\hline Allele & $\begin{array}{l}\text { Average } \\
\text { frequency }\end{array}$ & $F_{\text {IS.k }}$ & $F_{\text {IT.k }}$ & $\mathrm{F}_{\mathrm{ST}, \mathrm{k}}$ \\
\hline Est-1 ${ }^{\mathrm{a}}$ & $0 \cdot 1667$ & -0.0824 & 0.0109 & 0.0862 \\
\hline Est-1 ${ }^{\mathrm{b}}$ & 0.5905 & $-0 \cdot 1975$ & -0.1346 & 0.0525 \\
\hline Est $-1^{\mathrm{c}}$ & $0 \cdot 2428$ & $0 \cdot 1386$ & $0 \cdot 1992$ & 0.0703 \\
\hline $\begin{array}{l}\text { Weighted } \\
\text { average }\end{array}$ & & -0.0607 & 0.0100 & 0.0667 \\
\hline
\end{tabular}

zygotes for Est $-1^{\mathrm{c}}$ was observed. On the other hand, $F_{I S . a}$ is nonsignificant.

The weighted average of $F_{I S . k}$ values, $F_{I S}$, is negative, indicating a slight excess of heterozygotes when considering simultaneously all three alleles. The among-fruit heterogeneity (see among fruit analysis) compensates the excess of heterozygotes for Est $1^{\text {a }}$ yielding a slightly positive $\mathrm{F}_{\text {ITa }}$. However, this does not hold for the other alleles, which showed $F_{\text {IS.k }}$ and $F_{\text {ITk }}$ values of the same sign.

A global chi-square test for goodness of fit may be applied to test the significance of $F_{I T}$ (table 3 ). It shows that in the whole population the observed genotypic frequencies differ from the expected ones $\left(\chi_{3}^{2}=33.94 ; P<10^{-6}\right)$. As expected from the results of F-statistics, a partition of this chi-square demonstrates that the departure from the expectations are mainly due to alleles Est $-1^{\mathrm{b}}\left(\chi_{1}^{2}=12 \cdot 33\right)$ and $E s t-1^{\mathrm{c}}\left(\chi_{1}^{2}=7 \times 92\right)$, while for Est $1^{\mathrm{a}}$ considered individually the expected and observed frequencies agree very well $\left(\chi_{1}^{2}=0 \cdot 31\right)$.

All this information suggests that there are discrepancies between observed and expected genotypic frequencies that cannot be explained only as a result of the founder effect associated with the colonization of each fruit.

The $F_{S T}$ values were, however, relatively homogeneous, but it is worth noting that the highest value corresponded to Est $-1^{\mathrm{a}}$, which is the only one in which the F-statistics agree with the expectations for random differentiation.

Table 3 Comparison between observed and expected genotype frequencies by an $\chi^{2}$ test of goodness of fit

\begin{tabular}{lcl}
\hline Genotypes & Observed & Expected \\
\hline${\text { Est }-1^{\text {aa }}}^{\text {ab }}$ & 9 & $10 \cdot 44$ \\
Est $^{\text {ab }}$ & 85 & $62 \cdot 24$ \\
sst $^{\text {ac }}$ & 2 & $21 \cdot 88$ \\
Est $^{\text {bb }}$ & 79 & $92 \cdot 77$ \\
Est $^{\mathrm{bc}}$ & 70 & $65 \cdot 21$ \\
Est $^{\mathrm{bc}}$ & 19 & $11 \cdot 46$ \\
\hline
\end{tabular}

$\chi_{3}^{2}=33.94 ; P=2 \times 10^{-7}$. 
The randomness of differentiation may be tested in some cases by a method based on $\mathrm{Nei}$ (1965) which consists of the comparison of the observed with the expected correlations between allele frequencies (Santos et al., 1989). The expected correlation between the gene frequencies of the $m$ th and $n$th alleles may be estimated by the formula:

$$
r_{(m, n)}=-\left(p_{m} p_{n} /\left(1-p_{m}\right)\left(1-p_{n}\right)\right)^{1 / 2}
$$

(Nei, 1965; Nei and Imaizumi, 1966), where $p_{m}$ and $p_{n}$ are the arithmetic means of the allelic frequencies over the subpopulations studied.

The expected and observed correlations are shown in table 4 . The highest difference corresponded to the correlation between $E s t-1^{\mathrm{a}}$ and Est $-1^{\mathrm{c}}$, which tend to be more dissociated than expected. Unfortunately, with the present data it is not possible to test statistically these differences according to the method described by Sokal and Rohlf (1981, pp. 583-591). With the number of fruits obtained in the present study, the confidence interval covers almost the whole scale of negative correlations and it is almost impossible to detect significant differences.

Table 4 Observed and expected correlations between allelic frequencies of the Est-1 locus

\begin{tabular}{|c|c|c|}
\hline \multirow[b]{2}{*}{ Allelic pair } & \multicolumn{2}{|c|}{ Correlations } \\
\hline & Observed & Expected \\
\hline$E s t-1^{\mathrm{a}}-E s t-1^{\mathrm{b}}$ & -0.4385 & -0.5371 \\
\hline Est $\mathrm{1}^{\mathrm{a}}-$ Est $_{\mathrm{1}}^{\mathrm{c}} \mathrm{c}$ & -0.4674 & -0.2533 \\
\hline$E s t-1^{\mathrm{b}}-E s t-1^{\mathrm{c}}$ & -0.5896 & -0.6800 \\
\hline
\end{tabular}

\section{Within and among tree analysis}

If the rotting fruits are grouped according to the tree from which they were collected the results of the F-statistics are consistent with the previously described ones. There is a within tree excess of heterozygotes for $E s t-1^{\mathrm{b}}$ and deficiency of heterozygotes for $E s t-1^{\mathrm{c}}$. The $\mathrm{F}_{\text {IS.k }}$ for ${\text { Est }-1^{\mathrm{a}} \text { is }}^{\mathrm{a}}$ higher than that observed for individual fruits, but of lower magnitude than that of Est-1 ${ }^{\mathrm{b}}$.

The heterogeneity among trees is of the same order as that among fruits since the $F_{\mathrm{ST}}$ values were very similar. This heterogeneity, as in the analysis of rotting fruits does not compensate the within-tree departures from Hardy-Weinberg's expectations in respect to $E s t-1^{\mathrm{b}}$ and $E s t-1^{\mathrm{c}}$.

\section{Analysis of variation between host species}

A contingency table was made to compare genotypic frequencies between peach and peach $\times$ almond hybrid fruits. The results indicate that allelic and genotypic frequencies are homogeneous between the two kind of hosts $\left(\chi_{5}^{2}=3 \cdot 75 ; P=\right.$ $0 \cdot 568)$. The departures from Hardy-Weinberg's expectations were of the same order in both samples.

\section{DISCUSSION}

The population studied here exhibited variation at the Est-1 locus with an heterozygosity $(\mathrm{H})$ ( Nei 1975 ) of 0.57 . This value is very high taking into account the low genetic variability obtained in most previous isoenzymatic studies (Morgante et al., 1981; Kourti et al., 1985; Mukiama, 1985; Gasperi et al., 1987; Saidman et al., 1987). One explanation for this contrast is that the locus studied in this case is active during the pupal stage, while all the previous studies dealt with adult loci.

The population structure is quite different according to the life stage considered and, consequently, there may be differences in the amount of genetic variability detected in each stage. For the adults the environment may be considered as fine-grained (see Levins, 1968; Dobzhansky, 1970; Valentine, 1976) since an adult fly is able to visit many fruits during its life. On the contrary, once an egg is laid on a certain fruit, it must reach the prepupal stage (late third instar larvae) within this fruit, that is, its environment is coarse grained. The genetic strategy may therefore result in different degrees of variability in adult and previous stages. This hypothesis could be tested through the analysis of other systems in larvae or pupae.

The analysis of the genetic structure performed in the present study does not allow us to estimate with certitude the number of breeding pairs contributing to each rotting fruit because the differential behaviour of each allele does not allow us to reject the occurrence of selection. However, if this process is ignored, the number of founders of each breeding site may be obtained according to the expression:

$$
N=-1 /\left(2 \mathrm{~F}_{\text {IS }}\right) \text { (Long, 1986; p. 639). }
$$

and for the present population it would be about eight, i.e., four breeding pairs. Though this number is not a good estimate, it agrees with the assumption of a finite and small number of founders per rotting fruit. The among tree analysis leads to a 
similar conclusion, because with an average of two fruits analysed per tree, the $F_{I S}$ is nearly half that obtained among individual fruits, giving approximately eight breeding pairs per tree (or every two fruits).

The differential behaviour of the alleles and the discrepancies between observed and expected genotype frequencies indicate that some kind of selection must be acting either on the locus considered or on closely linked loci. The analysis of the expected and observed genotype frequencies and the correlation of frequencies of allelic pairs suggest that Est $-1^{\mathrm{a}}$ and $E s t-1^{\mathrm{c}}$ tend to be less associated than the expected, that is, the selection is acting against the heterozygotes Est-1 ${ }^{\text {ac }}$. However, the other heterozygous genotypes are in excess, in such a way that the whole frequency of heterozygotes is not in deficit.

In Drosophila buzzatii from Spain (Santos et al., 1989) the number of breeding pairs ovipositing on each Opuntia ficus-indica rotting pad was estimated in about five on the basis of the inversion polymorphism of the fourth chromosome pair, which behaved as neutral for larval viability. The $\mathrm{F}_{\mathrm{ST}}$ observed in that case, approximately 0.05 , was considered the consequence of random differentiation. On the other hand, the $\mathrm{F}_{\mathrm{ST}}$ for the second pair, which was a little higher $(0.07)$, was considered as the result of random differentiation plus larval viability selection caused by environmental heterogeneity.

In the present case, the value of $F_{S T}(0.067)$ is near the one obtained for the second chromosome pair of $D$. buzzatii, and from the similar structure of the population and the $F_{I S}$ indices, it seems to be reasonable to assume that the number of founders ovipositing on each breeding site is similar to the one estimated for that species, that is, the number of females ovipositing per fruit probably is not too different from the estimation of four. The low number of ovipositing females is not unexpected because females deposited a marking pheromone during ovipositor dragging on the fruit surface after egglaying that reduces the degree of host fruit discovery and oviposition by other medflies (Prokopy et al., 1978, 1987).

One possible source of error in such estimations would occur if each female is able to oviposit in several fruits instead of just one. The consequence of such situation would be a lower differentiation $\left(\mathrm{F}_{\mathrm{ST}}\right)$ than that expected for the estimated number of founders (according to $F_{I S}$ ). $F_{S T}$ represent the inbreeding coefficient caused by one generation of drift and it should be equal to $1 / 2 \mathrm{~N}$ (see Hedrick, 1983 , p. 245 ), i.e., $F_{\mathrm{ST}}$ should be equal to $-\mathrm{F}_{\mathrm{IS}}$ (see above). The actual results in the present work and in that of Santos et al. (1989) fitted very well with this expectation $\left(\mathrm{F}_{\mathrm{ST}}=-\mathrm{F}_{\mathrm{IS}}\right)$, supporting the assumption that each female oviposited virtually in just one fruit.

The comparison between genotype frequencies on the two kinds of hosts, peach and almond $x$ peach hybrids, did not show differences. Both allelic and genotypic frequencies are virtually the same and also the population structure does not vary in the different hosts. Since in both samples the deviation from Hardy-Weinberg expectations are the same, selection acts in the same way in both kinds of fruits.

The present results contribute to the analysis of the genetic structure of $C$. capitata populations giving a useful piece of information for genetic control programs if the estimation of the number of females contributing to each breeding site can be confirmed by studies based on other systems where the assumption of selective neutrality can be fulfilled. In any case, the assumption of a limited and small number of breeding pairs on each rotting fruit seems to be tenable and its estimation would be useful for determining the effective population size of natural populations of this insect pest.

\section{REFERENCES}

BEDO, D. G. 1986. Polytene and mitotic chromosome analysis in Ceratitis capitata. Can. J. Genet. Cytol, 28, 180-188.

CLADERA, J. L. 1981. Genética de alozimas en Ceratitis capitata. I. Dos alelos de la esterasa pupal. Mendeliana, 5, 33-38. DOBZHANSKY, TH. 1970. Genetics of the Evolutionary process. Coumbia University Press, New York-London.

DOBZHANSKY, T. H., AYALA, F. J., STEBBINS, G. L. AND VALENTINE, J. W. 1980. Evolución. Ed. Omega, Barcelona.

FERON, M. 1962. L'instinct de reproduction chez la mouche Mediterranéene des fruits. Rev. Pathol. Végét. Entom. Agric., 41, 1-129.

GASPERI, G., MALACRIDA, A. R. AND MILANI, R. 1987. Protein variability and population genetics of Ceratitis capitata. In Economopoulos, A. P. (ed.) Fruit Flies. Proceeding of the II International Symposium. Elsevier, pp. 149-157.

HEDRICK, P. W. 1983. Genetics of Populations. Science Books International, Boston.

KOURTI, A., LOUKAS, M. AND ECONOMOPOULOS, A. 1985. Genetic studies in medfly populations. Report on Research Coordination Meeting on the Development of Sexing Mechanisms in Fruit Flies. FAO/IAEA, Vienna (Mimeographed).

LEVINS, R. 1968. Evolution in Changing Environments. Princeton University Press, Princeton.

LI, C. C. AND HORVITZ, D. G. 1953. Some methods of estimating the inbreeding coefficient. Am.J. Hum. Genet., 5, 107-117.

LONG, J. C. 1986. The allelic correlation structure of Gainj- and Kalam-speaking people. I. The estimation and interpretation of Wright's F-statistics. Genetics, 112, 629-647. 
MORGANTE, J. S., DE SOUZA, H. M. L., DE CONTI, E. AND CYTRYNOWICZ, M. 1981. Allozymic variability in an introduced fruit fly pest Ceratitis capitata (Wiedeman), 1824, (Diptera-Tephritidae). Rev. Bras. Genet., 4, 183-191.

MUKIAMA, T, K. 1985. East African strains of Ceratitis capitata. Occurrence and enzyme variation. Report on Research Coordination Meeting on the Development of Sexing Mechanisms in Fruit Flies. FAO/IAEA, Vienna (Mimeographed).

NEI, M. 1965. Variation and covariation of gene frequencies in subdivided populations. Evolution, 19, 256-258.

NEI, M. 1975. Molecular Population Genetics and Evolution. North Holland/American Elsevier, Oxford-New York.

NEI, M. 1977. F-statistics and analysis of gene diversity in subdivided populations. Ann. Hum. Genet., 41, 225-233.

NEI, M. AND CHESSER, R. K. 1983. Estimation of fixation indices and gene diversities. Ann. Hum. Genet., 47, 253-259.

NEI, M. AND IMAIZUMI, Y. 1966. Genetic structure of human populations. I. Local differentiation of blood group gene frequencies in Japan. Heredity, 21, 9-35.

PROKOPY, R. J., ZIEGLER, J. R. AND WONG, T. T. Y. 1978. Deterrence of repeated oviposition by fruit-marking pheromone in Ceratitis capitata. J. Chem. Ecol, 4, 55-63.

PROKOPY, R. J., PAPAJ, D. R., OPP, S. B. AND WONG, T. T. Y. 1987. Intra-tree foraging behaviour of Ceratitis capitata fijes in relation to host fruit density and quality. Entomol. exp. appl., 45, 251-258.

RASMUSSEN, D. I. 1979. Sibling clusters and genotype frequencies. Am. Nat., 113, 948-951.

ROBERTSON, A. 1965. The interpretation of genotypic ratios in domestic animal populations. Anim. Prod., 7, 319-324.
SAIDMAN, B. O. AND NARANJO, C. A. 1982. Variaciones de esterasas en poblaciones de Prosopis ruscifolia (Leguminosae). Mendeliana, 5, 61-70.

SAIDMAN, B., VIllardi, J., Cladera, J., CIVETTA, A. AND LEANZA, C. 1987. Caracterización isoenzimática de una población natural de Ceratitis capitata. Actas XVIII Congr. Argent. Genét. (Buenos Aires), 60.

SANTOS, M., RUIZ, A. AND FONTDEVILA, A. 1989. The evolutionary history of Drosophila buzzatii. XIII. Random differentiation as a partial explanation of chromosomal variation in a structured natural population. Amer. Nat., 133, 183-197.

SOKAL, R. R. AND ROHLF, F. J. 1981. Biometry, 2nd edn. W. H. Freeman, New York.

TERAN, H. R. 1977. Comportamiento alimentario y su correlación a la reproducción en hembras de Ceratitis capitata (Wied.). Rev. Agronom. N.O. Argent., 14, 17-34.

VALENTINE, J. W. 1976. Genetic strategies of adaptation. In Ayala, F. J. (ed.) Molecular Evolution. Sinauer Sunderland, Massachusetts, pp. 78-94.

VILARDI, J. C. 1989. Un programa BASIC para calcular indices de fijación (F). Mendeliana, in press.

WRIGHT, S. 1951. The genetical structure of populations. Ann. Eugen., 15, 323-354.

WRIGHT, S. 1965. The interpretation of population structure by F-statistics with special regard to systems of mating. Evolution, 19, 395-420.

ZACHAROPOULOU, A. 1987. The salivary gland chromosomes of the Mediterranean fruit fly, Ceratitis capitata. In Economopoulos, A. P. (ed.) Fruit flies. Proceeding of the II International Symposium. Elsevier., 177 (Abstr.). 